\title{
LOGÍSTICA VERDE E A DESTINAÇÃO DO LODO DE ETA E DE ETE: UMA ABORDAGEM TEÓRICA
}

\author{
H. M. Leonel ${ }^{1, ~ *}$; M. A. Fernandes ${ }^{2}$; L. G. G. Mendes ${ }^{2}$; N. Oliveira ${ }^{1,2}$ \\ 1 Faculdade de Tecnologia de São José dos Campos - Professor Jessen Vidal \\ Av. Cesare Mansueto Giulio Lattes, 1350 - Eugênio de Melo, São José dos Campos/SP, \\ CEP.: 12247-014, Brasil. \\ Telefone: (12) 3905-2423 \\ 2 Faculdade de Tecnologia de Jacareí. \\ Av. Faria Lima, 155 - Jardim Santa Maria - Jacareí/SP, CEP.: 12328-070, Brasil. \\ Telefone: (12) 3953-7926 \\ *hosana.silva01@ fatec.sp.gov.br
}

\begin{abstract}
RESUMO: O objetivo deste trabalho é fazer um levantamento, através de revisão da literatura, das práticas da logística verde no transporte e armazenamento do lodo de Estação de Tratamento de Água (ETA) e de Estação de Tratamento de Esgoto (ETE). No processo de destinação do lodo do esgoto usa-se a logística para a acomodação e deslocamento deste material, que pode se tornar uma grande ameaça ao meio ambiente, caso não haja um controle e/ou reaproveitamento do mesmo. A logística verde realiza o armazenamento e o transporte do material da melhor forma, para minimizar os custos da empresa e as emissões de poluentes gerados. Desta forma, analisaram-se atividades que envolvem a logística verde no tratamento do logo de esgoto e indicaram-se algumas práticas possíveis que podem ser adotadas nas Estações de Tratamento de Esgoto.
\end{abstract}

PALAVRAS-CHAVE: meio ambiente; logística verde; lodo de esgoto; Estação de Tratamento de Esgoto.

ABSTRACT: The objective of this work is to make a survey, through a review of the literature, of the green logistics practices in the transport and storage of sludge from the Water Treatment Station and Sewage Treatment Station. In the process of disposal of sewage sludge, the logistics are used for the accommodation and displacement of this material, which can become a great threat to the environment if there is no control and / or reuse of it. Green logistics makes the storage and transport of the material in the most efficient way, to minimize the costs of the company and the emissions of pollutants. In this way, the activities involving the green logistics in the treatment of the sewage logo were analyzed and some possible practices that could be adopted in the Sewage Treatment Stations were indicated.

KEYWORDS: environment; green logistics; sewage sludge; Sewage Treatment Stations.

\section{INTRODUÇÃO}

O lodo de esgoto, também conhecido como biossólido, é um resíduo rico em matéria orgânica por conter microrganismos e nutrientes (QUINTANA, 2011). Ele é obtido ao final do processo de tratamento de águas, através das Estações de Tratamento de Efluentes ou Esgoto (ETEs) e pelas Estações de Tratamento de Água (ETAs). Se processado, manuseado e transportado de forma adequada, consegue-se reinseri-lo ao ciclo produtivo. 
Segundo Wetlands Construídos (2017), emprega-se o lodo de esgoto como recurso alternativo com êxito na atividade agrícola, florestal, na indústria civil (agregado leve, tijolos, cerâmica, cimento), na conversão em óleo combustível e recuperação de solos. O instrumento responsável pela gestão dessa atividade são as práticas da logística verde, cujo foco é distinto da logística reversa.

A logística reversa opera e controla o fluxo e as informações correspondentes, do retorno dos bens, após a venda e consumo, ao ciclo empresarial e industrial, por meio dos canais de distribuição reversa, somando-lhes valores de diversas naturezas (LEITE, 2003).

A logística verde é definida como a área da logística que se preocupa com os aspectos e impactos ambientais oriundos de toda atividade logística (DONATO, 2008). Esse instrumento preocupa-se com a diminuição da necessidade de acondicionamento ou aumento da eficiência de transporte, gerando ganho ambiental por ter como finalidade o desenvolvimento sustentável (ROGERS; TIBBEN-LEMBKE, 1998). Em adição, contribui para a elaboração de estratégias ambientalmente amistosas no decorrer de cadeias de suprimentos (QUIUMENTO, 2011).

Apesar das diferenças presentes, a logística verde está conectada a logística reversa por utilizá-la como uma ferramenta operacional, pois é por meio da logística reversa que a movimentação de materiais para devolução e reaproveitamento é efetuada (DONATO, 2008).

A logística verde entrou em pauta no início dos anos 1990. Desde então, os governos, as universidades e a comunidade empresarial, no mundo, prestaram atenção neste assunto. Porém, no Brasil, o desenvolvimento da logística verde ainda é relativamente atrasado (XIU; CHEN, 2012).

Tendo em vista os problemas ambientais que a sociedade vivencia, como destinação inadequada de resíduos, poluição do ar, mudança climáticas, entre outros, atitudes de prevenção à poluição e de reciclagem devem se tornar inerentes às atividades industriais e sociais (GIANNETTI; ALMEIDA, 2006).

Sabe-se que o lodo, quando não corretamente gerenciado, pode transmitir doenças, proliferar vetores, contaminar solos e água, ocasionando em enormes perdas ambientais e econômicas.

Dada a complexidade do lodo originado no processo de Tratamento de Efluentes, que requer armazenamento in loco, transporte e tratamento adequados, este trabalho apresenta a atividade relacionada à destinação desse resíduo. Ainda neste contexto, apresenta-se também alternativas de tratamento e destinação que visam a reduzir estas perdas, dentro dos princípios da logística verde. Desta forma, foram propostos os objetivos deste estudo.

\subsection{Objetivo geral}

O objetivo geral deste trabalho é fazer um levantamento, através de revisão da literatura, das práticas da logística verde no transporte e armazenamento do lodo de Estação de Tratamento de Água (ETA) e de Estação de Tratamento de Esgoto (ETE).

\subsection{Objetivo específico}

Para a consecução deste objetivo foram estabelecidos os objetivos específicos: fazer uma revisão da literatura; apresentar as práticas de gestão das atividades da logística verde e a sua relação com o transporte e armazenagem do lodo do esgoto.

\section{MATERIAS E MÉTODOS}

Para alcançar os objetivos propostos neste trabalho, foi feita uma abordagem teórica sobre o tema. Foram feitas pesquisas em artigos, dissertações e teses, bem como da legislação vigente.

A metodologia do processo de seleção de artigos foi estruturada em duas fases, com suas respectivas etapas, objetivos e resultados, de acordo com o Quadro 1. 
Quadro 1. Resultado dos procedimentos de escolha de referências para a revisão da literatura.

\begin{tabular}{|c|c|c|c|}
\hline Fases & Etapas & Objetivos & Resultados \\
\hline 1. Seleção de base de dados. & 1.1 & $\begin{array}{l}\text { Identificar áreas de } \\
\text { conhecimento e eixos de } \\
\text { pesquisas que representam o } \\
\text { fragmento da literatura } \\
\text { relativo ao tema e seleção das } \\
\text { bases de dados que } \\
\text { contemplam esse tema. }\end{array}$ & 4 bases \\
\hline \multirow[t]{4}{*}{ 2. Seleção dos estudos. } & 2.1 & $\begin{array}{l}\text { Definir as palavras-chave para } \\
\text { realização da pesquisa e } \\
\text { buscar nas bases de dados. }\end{array}$ & 60 artigos \\
\hline & 2.2 & $\begin{array}{l}\text { Analisar os títulos das } \\
\text { publicações e } \\
\text { artigos alinhados } \\
\text { selecionar } \\
\text { selecionados }) \text { não }\end{array}$ & 42 artigos \\
\hline & 2.3 & $\begin{array}{l}\text { Selecionar artigos com maior } \\
\text { reconhecimento científico. }\end{array}$ & 20 artigos \\
\hline & 2.4 & $\begin{array}{l}\text { Analisar os resumos e excluir } \\
\text { artigos desalinhados (6 artigos } \\
\text { e } 15 \text { estudos entre livros, sites } \\
\text { e dissertações de mestrado e } \\
\text { teses de doutorado excluídos). }\end{array}$ & 14 artigos \\
\hline
\end{tabular}

Fonte: Adaptado de Engelage et. al. (2016).

As bases de dados escolhidas para este trabalho, citadas no Quadro 1, são: Portal de Periódicos da CAPES (CAPES, 2018); Scielo (SCIELO, 2018); Emerald Insight (EMERALD INSIGHT, 2018) e Universidade Federal de Santa Maria (UFSM, 2018). Entende-se que tais bases contêm uma representatividade adequada para a abordagem a ser aplicada.

A maioria dos artigos encontrados não tratam especificamente da logística verde e sim da logística reversa. Isto é compreensível, já que a ideia relacionada a logística reversa partiu não só de aspectos econômicos, mas também da necessidade de atendimento à área ambiental.

\section{REVISÃO DA LITERATURA}

Neste capítulo foram revistos textos que subsidiem os conhecimentos necessários ao entendimento do trabalho apresentado. Foi realizada pesquisa na literatura específica apresentando um panorama sobre a logística verde, a Política Nacional de Resíduos Sólidos e algumas considerações sobre ETE.

\subsection{Logística Verde}

Segundo Donato (2008), as preocupações dos gestores da logística estão, na maioria das vezes, voltadas para as variáveis custo, tempo e economia, e não costumam abranger as questões ambientais. 
Para Engelage et al. (2016), as preocupações e a sensibilização com os efeitos das ações desordenadas como a poluição, o congestionamento, o esgotamento de recursos, a eliminação de resíduos perigosos, a geração de ruídos e a degradação ambiental tem feito com que a visão dos processos seja estendida também às questões sociais e ambientais, nas últimas décadas.

Segundo World Economic Fórum Accenture (2009), a humanidade produz cerca de 50.000 megatoneladas de gases de efeito estufa $\left(\mathrm{CO}_{2}\right)$ por ano e cerca de 2.800 megatoneladas podem ser atribuídas à logística e às atividades de transporte. Embora exista uma incerteza significativa nos números, parece possível que reduções de emissões poderiam ser alcançadas no médio prazo, implementando mudança em toda a cadeia de fornecimento, de ponta a ponta. A logística verde pode ser útil em vários setores da sociedade e, desta forma, pode contribuir para a redução das emissões de gases de efeito estufa, diminuição da contaminação de meios hídricos, conservação de fauna e flora, obtendo-se além disso, ganhos econômicos condizentes com os preceitos do desenvolvimento sustentável.

A Figura 1, a seguir, apresenta as áreas onde a logística verde pode trazer os benefícios citados acima, entretanto, sabe-se que muitos destes conceitos ainda estão em desenvolvimento e em discussão com toda a cadeia produtiva.

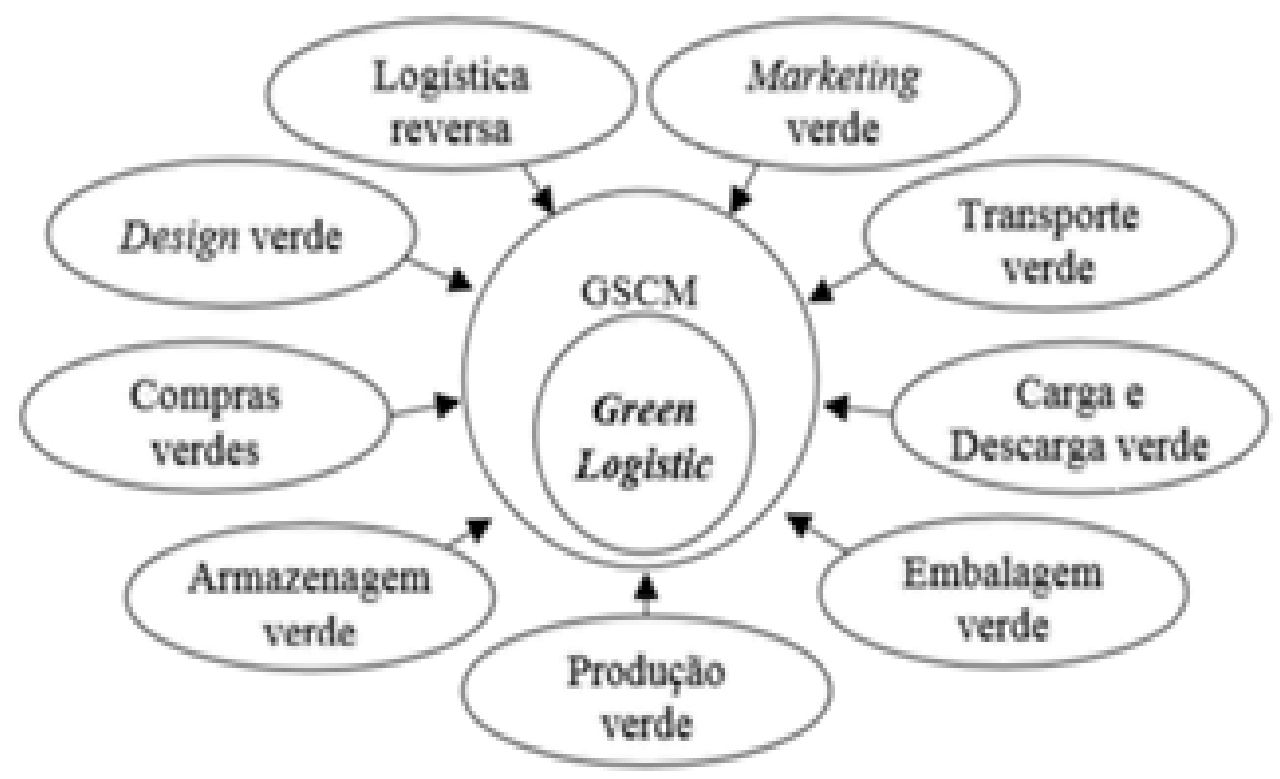

Figura 1. Taxonomia da logística verde (ENGELAGE et al., 2016).

A taxonomia da logística verde apresenta diversas alternativas ambientais e visa atender diversas demandas socioeconômicas e ambientais. Nesta mesma figura, a armazenagem, transporte e a logística reversa certamente são caminhos adequados para as questões relacionadas ao gerenciamento do lodo de esgoto.

\subsection{Política Nacional de Resíduos Sólidos}

O Governo Federal Brasileiro instituiu, em 2010, a Política Nacional dos Resíduos Sólidos (PNRS), a qual traz princípios e conceitos, como a responsabilidade compartilhada, que envolve todos os setores da sociedade na gestão dos resíduos sólidos, desde o produtor até o consumidor final. O lodo de esgoto é um resíduo originado no processo de tratamento em uma ETE, deste modo, a Política Nacional de Resíduos Sólidos prevê o seu correto tratamento e destinação, o que vai de encontro com a logística verde. 
Tendo em vista a preocupação e necessidade da gestão dos resíduos, o setor de tratamento de esgoto é capaz de beneficiar-se melhor, no âmbito ambiental, com as práticas sustentáveis da Logística (IWAKI, 2017).

A Lei 12.305, de 02 de agosto de 2010 (BRASIL, 2010) instituiu a Política Nacional de Resíduos Sólidos, que dispõe diretrizes relativas à gestão integrada e ao gerenciamento de resíduos sólidos. Foi regulamentada pelo Decreto 7.404, de 23 de dezembro de 2010, que também criou o Comitê Interministerial da Política Nacional de Resíduos Sólidos e o Comitê Orientador para a Implantação dos Sistemas de Logística Reversa

Essa lei é de extrema importância para estabelecer regulamentações para saber como gerir os materiais descartados, neste caso, o lodo de esgoto é um deles (BRASIL, 2010). A seguir, cita-se seus principais objetivos:

$\checkmark$ Proteção da saúde pública e da qualidade ambiental, estimulando padrões sustentáveis de produção e consumo de bens e serviços com desenvolvimento e aprimoramento de tecnologias limpas;

$\checkmark$ Não geração, redução, reutilização, reciclagem e tratamento dos resíduos sólidos, bem como disposição final ambientalmente adequada dos rejeitos;

$\checkmark$ Gestão integrada dos resíduos sólidos que busca compartilhar a responsabilidade pelo ciclo de vida dos produtos, envolvendo todos da cadeia de comercialização, como fabricantes, distribuidores, consumidores e órgãos públicos;

$\checkmark$ Incentivo à indústria da reciclagem, tendo em vista fomentar o uso de matériasprimas e insumos derivados de materiais recicláveis e reciclados;

$\checkmark$ Incentivo ao desenvolvimento de sistemas de gestão ambiental e empresarial voltados para a melhoria dos processos produtivos e ao reaproveitamento dos resíduos sólidos, incluídos a recuperação e o aproveitamento energético.

\subsection{Estação de Tratamento de Esgoto}

A Estação de Tratamento de Esgoto (ETE) pode ser determinada como uma planta industrial, cuja matéria-prima é o esgoto bruto e, como produto principal, o esgoto tratado, ou seja, um efluente que atinge aos padrões exigidos por lei, para possam ser lançados ao meio ambiente.

A ETE é uma estrutura preparada para que, através de processo físicos, químicos e/ou biológicos, atinja o máximo as condições de depuração que ocorrem na natureza, examinando-os e permitindo o lançamento, no meio ambiente, de um efluente já consideravelmente refinado. Este processo acontece numa determinada área específica, na qual pode-se supervisionar e exceder controle sobre o sistema de depuração (ACHON; CORDEIRO, 2015).

Em uma ETE, os resíduos da água passam por vários processos de tratamento, com o objetivo de separar ou diminuir a quantidade da matéria poluente da água. A quantidade gerada de lodo de esgoto cresce, gradativamente, ao aumento dos serviços de coleta e tratamento de esgoto que, por sua vez, deve acompanhar o crescimento da população (WETLANDS CONTRUÍDOS, 2017).

Há alguns anos, estimativas apontavam uma produção nacional de 150 a 220 mil toneladas de matéria seca, considerando que o tratamento de esgoto atingia cerca de $30 \%$ da população urbana. Em média, estima-se que cada ser humano produza cerca de $120 \mathrm{~g}$ de sólidos secos diários lançados nas redes de esgoto. $\mathrm{O}$ tratamento de esgoto, por ser procedimento biológico, resulta em dois tipos de resíduos: o efluente líquido, pronto para ser devolvido ao meio ambiente, e o lodo (primário e secundário), que é um material pastoso, com grande concentração de micro-organismos, sólidos orgânicos e minerais (AHAMAD, 2016).

O uso do lodo já é realizado em outros países há bastante tempo, sendo o reuso agrícola o método mais utilizado. No Brasil, as alternativas de reuso ainda são pouco utilizadas e a destinação mais comum é o aterro sanitário (QUINTANA et al., 2011). 


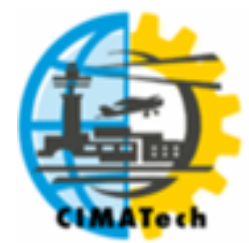

De acordo com a Resolução CONAMA No 375/2006 (BRASIL, 2006), que define critérios e procedimentos para o uso agrícola de lodos de esgoto gerados em estações de tratamento de esgoto sanitário e seus e derivados, os lodos gerados em sistemas de tratamento de esgoto devem ser submetidos a processos de redução de patógenos e da atratividade de vetores, para que possam ser utilizados na agricultura.

\subsection{Processo de Tratamento e Destinação do Lodo do Esgoto}

Lodo do esgoto é o resíduo de todos os sistemas de tratamento de efluentes urbanos resultantes dos processos de tratamento de esgoto sanitário, podendo ser líquido ou sólido, oriundo do tratamento de esgotos, cuja composição predominantemente orgânica varia de acordo com sua origem.

Conforme Brasil (2004), o lodo de esgoto ou biossólido pode ser classificado como:

$\checkmark$ Lodo primário: é o lodo oriundo de processos de tratamento primário, obtido por sedimentação ou flotação;

$\checkmark$ Lodo digerido: é o lodo cuja biodegradação foi constituída por processos aeróbios ou anaeróbios, com redução de SSV superior a 40\%;

$\checkmark$ Lodo estabilizado: é o lodo cuja biodegradação foi realizada por processos aeróbios ou anaeróbios de forma a não apresentar potencial de geração de odor;

$\checkmark$ Lodo digerido higienizado: é o lodo submetido ao processo de tratamento com eficiência de redução de patógenos, entre outros.

O tratamento do lodo do esgoto é aquele em que a redução das cargas orgânicas ocorre pela ação de microrganismos de forma em que o mesmo possa ser utilizado como adubo orgânico, corretivo em solos agrícolas, componente de materiais de construção civil, asfalto etc. (BRASIL, 2004).

De acordo com Wetlands Construídos (2017), o lodo de ETEs está sendo despejado em cursos de água sem nenhum tipo tratamento. Essa prática é apontada, pelos órgãos ambientais, como causadora de possíveis riscos à saúde pública e à vida aquática.

Calcula-se que a produção de lodo de ETEs, nos municípios atendidos pela Sabesp, no Estado de São Paulo, seja de, aproximadamente, 90 toneladas por dia. Observou-se uma enorme variabilidade nos quantitativos de lodos gerados ao longo de um ano em cada ETE. (IWAKI, 2017).

Normalmente, de novembro a março, no período chuvoso, ocorre uma maior produção de lodo, época em que há piora na qualidade das águas dos mananciais, representada pelos parâmetros cor atípica e turbidez, necessitando, consequentemente, da aplicação de grandes quantidades de produtos químicos para o tratamento, notadamente de coagulantes (VON SPERLING; GONÇALVES, 2001).

As maneiras mais eficientes ou de maior potencial de utilização para o Estado de São Paulo são: fabricação de cimento, disposição no solo, cultivo de grama comercial, fabricação de tijolos, solo comercial, compostagem e plantações de cítricos. O lodo também poderá ser utilizado para a melhoria da sedimentabilidade em águas de baixa turbidez, recuperação de coagulantes e controle de $\mathrm{H}_{2} \mathrm{~S}$ (sulfeto de hidrogênio) (URBAN, 2016).

Além das utilizações benéficas citadas, muitas vantagens têm sido observadas, quando os lodos de ETEs são lançados em redes coletoras de esgotos ou diretamente nas estações de tratamento de esgotos. Os tratamentos necessários envolvem processos de adensamento, desaguamento, estabilização e higienização, dependendo do destino. O adensamento e o desaguamento visam principalmente à redução do volume de água e a redução do volume do lodo, respectivamente (BATISTA, 2015).

O controle do lodo tem por finalidade reduzir a quantidade de patógenos, eliminar os maus odores e inibir, reduzir ou eliminar o potencial de putrefação. A limpeza do lodo visa garantir um 
nível de patogenicidade que, ao ser exposto ao solo, não cause riscos à população e ao meio ambiente. Apenas depois da realização desse procedimento é que o lodo estará pronto para ser deslocado (AHMAD, 2016).

O tempo para conclusão da limpeza depende do procedimento adotado pela unidade de gerenciamento e de sua eficiência, variando de zero, na secagem térmica, a 30/60 dias na calefação. Os procedimentos de calefação do lodo consistem na mistura do cal virgem $(\mathrm{CaO})$ em proporções variadas, em função do volume seco do lodo, de modo a elevar o aumento do $\mathrm{pH}$ numa reação exotérmica que inativa até $90 \%$ dos organismos patogênicos e acelera o processo de evaporação, podendo atingir temperaturas de até $80^{\circ} \mathrm{C}$ (D AVIGNON; LA ROVERE, 2012).

É importante salientar que, para uma destinação correta do lodo de esgoto, os gestores responsáveis pelo processo, além de possuírem conhecimento técnico sobre os tratamentos envolvidos, necessitam de conhecimentos logísticos. A aplicação da logística para planejar, manusear, armazenar e transportar os resíduos é essencial para que os procedimentos sejam bemsucedidos. A relação da logística verde e reversa estão presentes em toda a cadeia de reuso do lodo, bem como as aplicações da logística verde, que tem por conceitos, entre outros aspectos, a ausência de reaproveitamento e com o crescente aumento da emissão de resíduos ao meio. (IWAKI, 2017).

A integração dos processos logísticos para identificar as inúmeras alternativas que a logística verde possui, entre eles, equipamentos, materiais e instalações de fatores determinantes para garantir uma eficiência de alto valor, minimizar custos e ter a certeza que seja garantido que os processos se tornem cada vez menos poluidores do meio ambiente (MCKINNON, 2010)

Da mesma forma, conhecer e aplicar os conceitos relativos à logística reversa e à logística verde é igualmente necessário para que se alcance o equilíbrio entre economia e meio ambiente (DONATO, 2008).

Para (GODOY, 2013), a aplicação do lodo na agricultura parece ser a forma mais difundida de utilização do resíduo. No entanto, outras formas de aproveitamento também estão sendo estudadas:

1. Reaproveitamento Industrial

- Fabricação de tijolos e cerâmicas;

- Produção de agregado leve para construção civil;

- Produção de cimento.

2. Reaproveitamento Agrícola

- Fertilizante orgânico e compostagem;

- Recuperação de solos degradados.

A incorporação do lodo de esgotos na fabricação de produtos cerâmicos, como telhas, tubos, tijolos e lajotas, tem-se mostrado uma alternativa viável de destinação adequada. O lodo é adicionado ao processo durante a etapa de preparação da massa cerâmica e auxilia na correção de umidade. Isso pode ser feito manualmente, com pás carregadeiras, utilizando-se equipamentos apropriados (GERADO; SANIT, [s.d.]).

\subsection{Transporte, movimentação e armazenagem do lodo}

De acordo com Von Sperling (2001), os custos com transporte têm grande influência sobre os custos totais da operação logística. No caso do lodo, os custos com movimentação e transporte estão diretamente ligados ao seu teor de umidade e, portanto, de acordo com o tipo de biossólido produzido, como pode ser observado no Gráfico 1. 
Gráfico 1. Variação do teor de umidade média, de acordo com o tipo de biossólido produzido e a redução do número de caminhões necessários para o transporte.

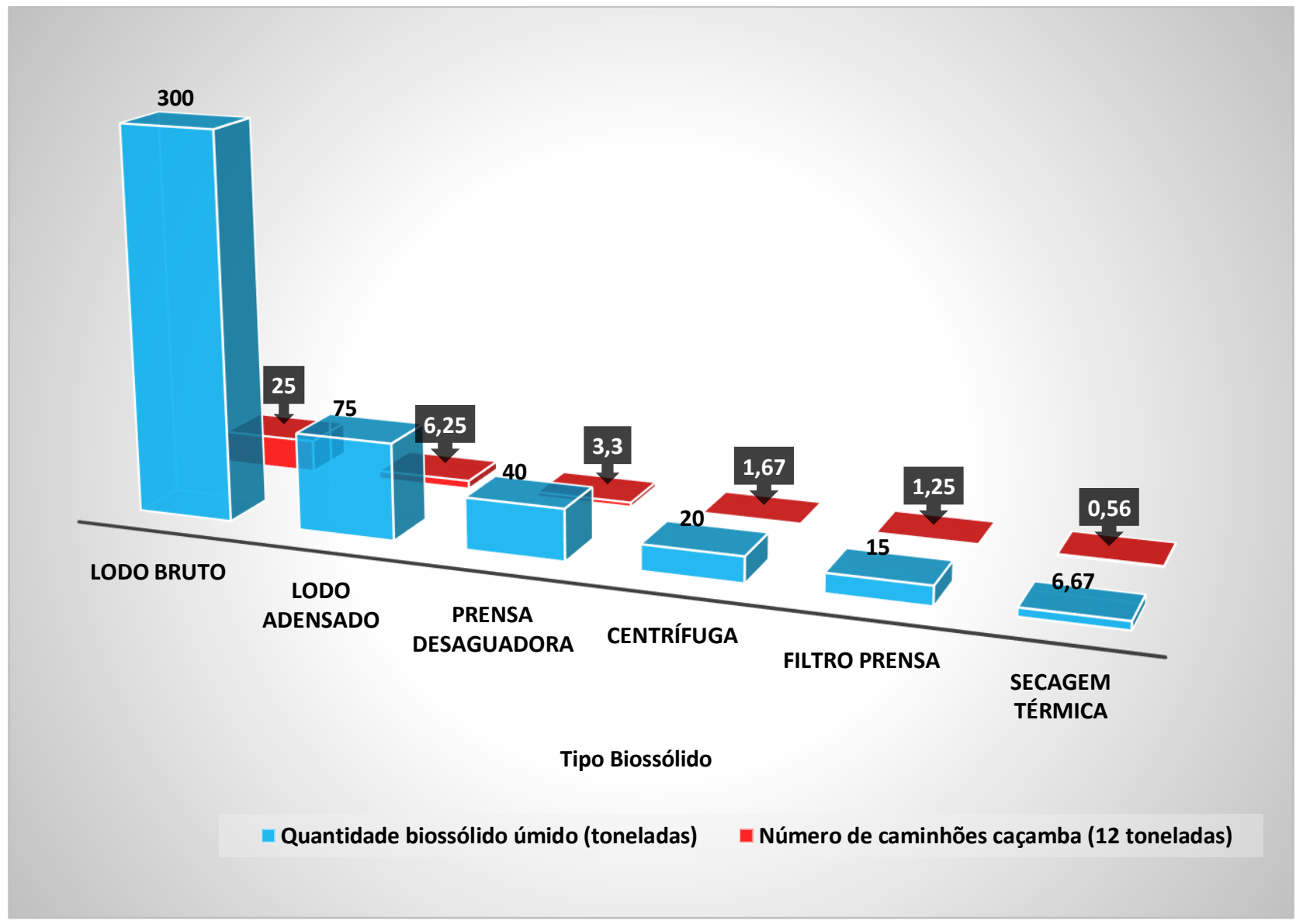

Fonte: Autores (2018).

Pelo Gráfico 1 pode-se ver que quando a quantidade de biossólido úmido diminui de 300 para 6,67 toneladas, o número de caminhões caçamba diminui cerca de $98 \%$ (de 25 a 0,56, em número absoluto). Isso ocorre quando o lodo bruto é substituído pelo biossólido de secagem térmica. Assim, quando o lodo passa por algum tipo de tratamento que reduz sua umidade, há uma redução drástica no número de caminhões caçamba e, em consequência, há uma grande redução nos gastos com transporte do lodo.

O custo de transporte é um parâmetro essencial para a viabilidade econômica do uso agrícola do lodo de esgoto. Quanto maior o volume a ser transportado por viagem, menor o custo unitário de transporte (GODOY, 2013 ). O lodo antes de ir para seu último destino tem que ser transportado dentro da própria Estação de Tratamento de Esgoto (ETE).

Segundo Von Sperling (2001), para essa movimentação, geralmente, são utilizadas esteiras transportadoras ou caçambas do tipo Brook com capacidade média de $5 \mathrm{~m}^{3}$ cada, acopladas a caminhões com dispositivos hidráulicos de carga e descarga.

O carregamento de caminhões pode ser realizado com pás carregadeiras de rodas ou retroescavadeiras e devem possuir carrocerias totalmente vedadas, serem equipados com sistema de trava que impeça a abertura da tampa traseira, possuir lona plástica para cobertura, cone de sinalização, pá ou enxada e luvas de látex (VON SPERLING, 2001).

Além de respeitar a capacidade volumétrica da caçamba transportadora, outros cuidados devem ser tomados no transporte de biossólidos, lembrando que é de total responsabilidade da 
empresa geradora do resíduo. Deverão ser observadas também as condições das estradas a percorrer, distância, tipos de veículos, limpeza dos pneus ou de qualquer outra parte do veículo ao sair da ETE, não carregar nem transportar em dias chuvosos se a operação não puder ser realizada em ambiente e caminhões cobertos (VON SPERLING, 2001).

\section{CONCLUSÃO}

Com base na literatura consultada, verificou-se que a logística verde deve ser uma prática recorrente na gestão não só de lodos de ETA e ETE, mas também das demais atividades causadoras de impactos ambientais, que tem por condição primordial, a utilização de recursos naturais.

Verificou-se também que esta é uma prática em que os setores produtivos estão se adaptando às novas exigências ambientais, visto que toda a cadeia produtiva e de suporte ainda estão em condições de formação de conceitos, elaboração de equipamentos e leis que orientam e atentam as novas demandas socioambientais.

Outro ponto interessante está relacionado à transformação e utilização do lodo como recurso alternativo na atividade agrícola, florestal, na indústria civil, na indústria de combustíveis alternativos, dentre outras possibilidades. Este aspecto é bastante importante, já que a transformação do lodo e sua respectiva utilização proporcionam uma melhor gestão ambiental, reduzem etapas da logística reversa e propiciam benefícios econômicos.

\section{REFERÊNCIAS BIBLIOGRÁFICAS}

ACHON, L. C.; CORDEIRO, J.S. Destinação e Disposição Final do Lodo Gerado em ETA: Lei 12.305/2010. XIX Exposição de Experiências Municipais em Saneamento. Poços de CaldasMG, 2015, maio, p. 1-8. http://www.trabalhosassemae.com.br/sistema/repositorio/2015/1/trabalhos/103/151/t151t1e1a2015. pdf. Acesso em: 03/04/2018.

AHMAD, T.; AHMAD, K.; ALAM, M. Sustainable Management of Water Treatment Sludge Though 3 'R' Concept. Journal of Cleaner Production, 2016, february, p.1-13.

BATISTA, L. F. Lodos Gerados nas Estações de Tratamento de Esgotos no Distrito Federal: um estudo de sua aptidão para o condicionamento, utilização e disposição final. Dissertação de Mestrado em Tecnologia Ambiental e Recursos Hídricos, Faculdade de Tecnologia, Departamento de Engenharia Civil e Ambiental. Universidade de Brasília, Brasília, 2015.

BRASIL. Ministério do Meio Ambiente. Conselho Nacional do Meio Ambiente - CONAMA. Versão 1 da Proposta de Resolução CONAMA sobre uso agrícola de lodo de esgoto elaborada na $2^{\mathrm{a}}$ Reunião do GT Lodo de Esgoto. 17 a 18 de fevereiro de 2004.

BRASIL (2006). Resolução CONAMA. N 380, de 31 de outubro de 2006. Retifica a Resolução CONAMA no 375/06 - Define critérios e procedimentos para o uso agrícola de lodos de esgoto gerados em estações de tratamento de esgoto sanitário e seus produtos derivados, e dá outras providências. Conselho Nacional do Meio Ambiente - CONAMA, Ministério do Meio Ambiente, Conselho Nacional do Meio Ambiente, 2006, 32 p. 
BRASIL (2006). Resolução CONAMA No 375, de 29 de agosto de 2006. Define critérios e procedimentos, para o uso agrícola de lodos de esgoto gerados em estações de tratamento de esgoto sanitário e seus produtos derivados, e dá outras providências. Ministério do Meio Ambiente, Conselho Nacional do Meio Ambiente, 2006, 32 p.

BRASIL (2010). Lei No 12.305 de 02 de agosto de 2010. Política Nacional de Resíduos Sólidos. Congresso Nacional, Brasília, DF, 2010.

CAPES. Disponível em www.periodicos.capes.gov.br/. Acesso em: 03/04/2018.

DAVIGNON, A. L.; LA ROVERE, E. L. Manual de Auditoria Ambiental de Estações de Tratamento de Esgotos. Rio de Janeiro: Qualitymark Editora, 2012.

DONATO, V. Logística Verde. Rio de Janeiro: Editora Ciência Moderna Ltda, 2008.

EMERALD INSIGHT. Disponível em https://emeraldinsight.com. Acesso em: 03/04/2018.

ENGELAGE, E.; BORGERT, A.; SOUZA, M. A. Práticas de Green Logistic: uma abordagem teórica sobre o tema. Revista de Gestão Ambiental e Sustentabilidade - RGeAS, Universidade Nove de Julho, Brasil: v.5, n.3, septiembre-diciembre, 2016, p. 36-54.

GIANNETTI, B. F.; ALMEIDA, C. M. V. B. Ecologia industrial: conceitos, ferramentas $e$ aplicações. São Paulo: Editora Blucher, 2006.

GERADO; SANIT. Resíduos sólidos do saneamento: processamento, reciclagem e disposição final. [s.l: s.n.].

GODOY, L. C. Revista Científica On-line - Tecnologia, Gestão e Humanismo, [s. 1.], v. 2, n. 1, p. 79-90, 2013. Disponível em http://www.fatecguaratingueta.edu.br/revista/index.php/RCOTGH/article/view/43/26. Acesso em: 09/10/2018.

GODOY, L. C. A logística na destinação do lodo de esgoto. Revista Científica On-line. Faculdade de Tecnologia de Guaratinguetá, V. 2, nº 1, 2013.

IWAKI, G. Destinação Final de Lodos de ETAs e ETEs. Portal Tratamento de Água, 2017. Disponível em https://www.tratamentodeagua.com.br/artigo/destinacao-final-de-lodos-de-etas-eetes/. Acesso em: 04/04/2018.

LEITE, P. R. Logística reversa: Meio Ambiente e Competividade. São Paulo: Editora Pearson Prentice Hall, 2003.

MCKINNON, A. et al. Green Logistics: The Carbon Agenda. LOGFORUM, 2010.

MURPHY, R. P; POIST, R. F. Green Perspective and Practices a "comparative logistics" study. Supply Chain Management: An International Journal, v.8, n. 2, p. 122-131,2003.

QUINTANA, N. R. G; CARMO, M. S.; MELO, W. J. Lodo de Esgoto como Fertilizante: produtividade agrícola e rentabilidade Econômica. Núcleos, 2011. v.8, n.1, abr., p.183-192. 
QUIUMENTO, F. Logística Verde: uma nova visão para a logística com atividade humana integrada ao ambiente. 2011. 2 Disponível https://knowledgeispowerquiumento.wordpress.com/article/logistica-verde-2tlel7k7dcy4s-90/. Acesso em: 06/04/2018.

ROGERS, D. S.; TIBBEN-LEMBKE, R. S. Going Backwards: reverse logistics trends and practices. Reverse Logistics Executive Council, 1998, Reno, Nevada. Disponível em: http://www.abrelpe.org.br/imagens_intranet/files/logistica_reversa.pdf. Acesso em: 03/05/2018.

SCIELO. Disponível em: www.scielo.org. Acesso em: 03/04/2018.

TSUTIYA, M. T; HIRATA, A.Y. Aproveitamento e disposição final de lodos de estações de tratamento de água do Estado de São Paulo. In anais do $21^{\circ}$ Congresso Brasileiro de Engenharia Sanitária e Ambiental. João Pessoa - PB, 2001.

UFSM. Disponível em https://periodicos.ufsm.br. Acesso em: 03/04/2018.

VON SPERLING, M. Lodo de Esgotos: tratamento e disposição final. Belo Horizonte: Departamento de Engenharia Sanitária e Ambiental - UFMG; Companhia de Saneamento do Paraná, 2001. 484p.

WETLANDS CONSTRUÍDOS. Lodo de Esgoto: tecnologias de tratamento e formas de destinação. Disponível em https://www.wetlands.com.br/single-post/2017/06/23/Lodos-de-esgoto-tecnologiasde-tratamento-e-formas-de-destina\%C3\%A7\%C3\%A3o. Acesso em: 02/04/2018.

WORLD ECONOMIC FÓRUM ACCENTURE. Supply chain decarbonization: the roleof logistics and transport in reduce ng supply chain carbon emissions. 2009.

XIU, G.; CHEN, X. Research on Green Logistics Development at Home and Abroad. Journal of Computers, 2012.v.7, n.11, nov., p. 2765-2772. 